\title{
Visualização e Análise da Trajetória de Aprendizagem Realizada no Currículo no Ensino Superior
}

\author{
Léo Manoel Lopes da Silva Garcia ${ }^{1}$, Raquel Salcedo Gomes ${ }^{2}$
}

${ }^{1}$ Faculdade de Ciências Exatas - Curso de Ciências da Computação - Universidade do Estado de Mato Grosso (UNEMAT) - Barra do Bugres - MT - Brasil

${ }^{2}$ Programa de Pós-Graduação em Informática na Educação - Universidade Federal do Rio Grande do Sul (UFRGS) - Porto Alegre - RS - Brasil

\{leoneto\} @unemat.br, \{raquel.salcedo\} @ufrgs.br

\begin{abstract}
The academic trajectory in higher education can generate results such as graduating, retention and dropout. There are several paths that can take the student to each of these results and, regardless of the path to follow, the curriculum is the backbone of that path. Thus, this article discusses the relevance of investigating the visibility of the trajectory in the higher education curriculum. In this perspective, an environment is proposed to support teachers in the evaluation and maintenance of the curriculum, enabling the visualization of the results of the interaction between students and the curricular components throughout their trajectory along the course. A test of the environment is carried out by analysing the case of a Computer course.
\end{abstract}

Resumo. A trajetória acadêmica no ensino superior pode gerar resultados como diplomação, retenção e evasão. Há uma variedade de trajetos que podem levar o aluno a cada um desses resultados e, independente do caminho a trilhar, o currículo é a espinha dorsal desse trajeto. Assim, neste artigo se discute a relevância de investigar a visibilidade da trajetória no currículo do ensino superior. Nesta perspectiva, é proposto um ambiente para apoiar os docentes na avaliação e manutenção do currículo, possibilitando a visualização dos resultados da interação dos acadêmicos com os componentes curriculares ao longo de sua trajetória no curso. Uma experimentação do ambiente é realizada com análise de um curso de Ciências da Computação.

\section{Introdução}

Um ambiente educacional representa um sistema organizacional, constituído pelas diversas relações das pessoas que o compõe, caracterizado pelas diferentes concepções acerca das políticas e objetivos educacionais em relação à formação dos alunos e da sociedade como um todo [Waszak 2018]. Tal formação, infere a existência de um processo de transformação e construção do indivíduo proporcionado através das atividades educacionais, formalizada pelo currículo.

Nota-se, portanto, que existe uma intencionalidade da instituição e dos docentes no planejamento e na implementação das atividades de ensino-aprendizagem; planejase uma sucessão de acontecimentos que deverão suceder na vida de cada estudante e que influenciarão suas trajetórias de vida [Canto Filho 2016]. Todavia, diversos fatores 
impõem divergências entre o que é planejado e o que é realizado. No ensino superior, isso ocorre de forma mais acentuada, uma vez que os alunos têm a liberdade de matricular-se em diferentes disciplinas a cada fase do curso, estabelecendo sua própria trajetória e, consequentemente, seus próprios resultados.

Esta liberdade de escolha e percursos possíveis faz com que existam distintas experiências do acadêmico com o currículo, refletidas em diferentes resultados alcançados tais como diplomação, evasão e retenção (permanência no curso além do prazo previsto para integralização). Embora diversos estudos explorem constantemente o uso de dados acadêmicos e socioeconômicos na investigação de problemáticas como evasão, reprovação e retenção, a estrutura do currículo também desempenha um grande papel no desenvolvimento do conhecimento e na performance dos alunos [Anuradha e Velmurugan 2015].

Reitera-se que o trajeto curricular realizado pelo aluno não é fruto somente de suas escolhas, mas também de seu desempenho, pois reprovações geram dependências que norteiam as escolhas das próximas matrículas e podem impor restrições por exigências de pré-requisitos, choques de horário, dentre outros. Faz-se necessário questionar se, de maneira oposta, as escolhas têm influência no desempenho. Esta dinâmica pode ser determinística para confirmar ou não as expectativas educacionais daqueles que elaboraram um plano curricular. Sobre isso, Leoniek (2018) afirma em seus resultados a importância de nunca tomar o currículo como imutável e garantido, e assim descreve:

Isso permite uma compreensão de currículos e trajetórias de aprendizagem como algo que não é fixo nem dado, mas sempre aberto para mudar e melhorar. O currículo a esse respeito poderia ser visto como uma entidade dinâmica, de evolução lenta, em vez de um programa fixo estático. (tradução nossa) [Leoniek 2018 pág. 229]

Neste sentido, Hall (2014) discorre que, independentemente do contexto de construção ou implementação, a avaliação contínua dos objetivos, processos e resultados no currículo é fundamental. Ela retrata ainda a tensão existente na tarefa de determinar os critérios desta avaliação, que vão, por exemplo, desde o desempenho acadêmico até habilidades e competências desenvolvidas ou não.

Assim, este estudo objetiva investigar a trajetória curricular realizada pelos alunos em comparação à trajetória planejada pelo currículo do curso, com o entendimento de que tornar as trajetórias de aprendizado explícitas e visíveis pode ajudar a promover importantes reflexões e potencialmente influenciar decisões para melhorar a qualidade de oferta de um curso. Para tanto, é proposta a implementação de uma ferramenta para amparar a análise da trajetória curricular percorrida com base nas matrículas e desempenho dos acadêmicos, que atue como um ambiente colaborativo entre os envolvidos na concepção, implementação e avaliação de um currículo.

\section{Trajetórias de Aprendizagem}

A concepção deste construto dentro da abordagem educacional traz uma abstração de um trajeto temporal, em que etapas em um caminho podem ser estabelecidas com base no tempo ou na conclusão de uma instrução. Essa orientação estabelece que o principal a ser investigado e compreendido é como o conhecimento e as crenças dos alunos 
mudam em função das práticas instrucionais que ocorrem ao longo do tempo [Confrey 2015].

É importante destacar que trajetória de aprendizagem não se trata de sequenciamento de conceitos e conteúdo, mas sim, da preocupação com a experiência vivida durante os processos instrucionais e, com isso, um exame nas transições ocorridas no desenvolvimento do aluno, de forma que o percurso tenha significado para ele. O construto figura como uma relevante abordagem a ser utilizada na construção de currículos, como descrito por Clements e Sarama (2014):

\begin{abstract}
A trajetória de aprendizagem é um dispositivo cujo objetivo é apoiar o desenvolvimento de um currículo ou de um componente do currículo. O termo currículo deriva da palavra latina para corrida, referindo-se ao curso de experiências pelas quais os alunos crescem e se tornam adultos maduros. Assim, a noção de um caminho, ou trajetória, sempre foi central para o desenvolvimento e estudo do currículo. (tradução nossa) [Clements e Sarama 2014 pág. 1-2]
\end{abstract}

Clements e Sarama (2014) descrevem que cada trajetória de aprendizagem possui 3 partes: 1 - objetivo, 2 - progressão no desenvolvimento e 3 - atividades instrucionais. Utilizando essa concepção para basear o currículo no ensino superior tem-se a formação dos acadêmicos com habilidades e competências do perfil profissional do curso (objetivo). Os acadêmicos aprendem a cada nível sucessivo implementados em semestres ou fases do curso (progressão no desenvolvimento) por meio do cumprimento de disciplinas previstas, cada qual com sua especificidade e atividades instrucionais próprias.

Assim, com o pressuposto de aproveitar da melhor maneira possível o período previsto para graduação e alcançando os objetivos educacionais, o currículo fundamenta-se principalmente em disciplinas obrigatórias, requisitos e sequências prédeterminadas. Consequentemente, isso reverbera na forma como o desenvolvimento do currículo e da trajetória de aprendizagem podem ser discutidos. Como resultado, espera-se que o percurso recomendado pelo curso indique aos alunos um melhor conjunto de disciplinas a serem cursadas em cada um dos semestres [Barbosa 2018], contudo esta recomendação nem sempre é seguida e os alunos constroem incontáveis tipos de percursos.

Levando essas características em consideração, Leonick (2018) coloca em questão a relevância e o desafio de organizar o conteúdo de forma a garantir que os alunos alcancem os objetivos de aprendizagem, ainda que exista esta liberdade de escolha na composição do programa de estudos. Assim, faz-se necessária a constante avaliação dos resultados alcançados, que podem demonstrar quais e como cada objetivo foi alcançado.

\title{
3. Trabalhos Relacionados
}

Ozudogru (2018) afirma que a avaliação curricular é essencial para o desenvolvimento, implementação e manutenção do currículo, em que os pontos fortes e fracos do currículo podem ser identificados bem como a eficácia de sua entrega após a implementação, sendo crucial para a qualidade da educação e do programa. Dada essa importância, surge uma demanda por metodologias e instrumentos para amparar essas 
avaliações e monitorar a implementação dos currículos, de forma a proporcionar a visibilidade dos componentes curriculares e a interação obtida na execução do curso.

Lima (2019) realiza uma análise de dados acerca dos percursos curriculares realizados por alunos que concluíram o curso de Ciência da Computação em uma instituição superior pública, com o objetivo de propor melhorias no projeto pedagógico do curso. $\mathrm{O}$ estudo possui como enfoque principal três questões fundamentais: o índice de alunos que cursam as disciplinas no prazo recomendado, como os alunos distribuem as disciplinas que não cursaram no período recomendado e quais são as proporções das situações dos alunos na primeira tentativa de cursar as disciplinas.

Em Barbosa (2018), são utilizadas técnicas de mineração de dados para avaliar a estrutura de um currículo com base em dados acadêmicos coletados de estudantes de graduação também em Ciências da Computação. Uma ferramenta foi desenvolvida, a qual possibilita verificar a correlação entre as disciplinas e também a previsão de notas com base no desempenho anterior do aluno antes de ingressar em uma determinada disciplina.

Diferente dos trabalhos anteriores, em que as abordagens contemplam fornecer dados para os gestores educacionais e educadores avaliarem a estrutura do currículo, Machado (2018) explora a aprendizagem adaptativa em e-learning utilizando uma abordagem evolutiva para o sequenciamento curricular adaptativo. A investigação proposta busca atender uma demanda de sistemas educacionais adaptativos com o objetivo de encontrar a melhor sequência de recursos educacionais que satisfaçam os objetivos, características e preferências de aprendizagem do aluno.

Neste trabalho é considerada a perspectiva dos gestores educacionais e docentes. Assim como em Lima (2019), as fases de ofertas recomendadas e as fases em que de fato cada disciplina é cursada serão investigadas, porém, adicionando a esta investigação o resultado final (aprovação ou reprovação) obtido em cada situação e abordando todos acadêmicos não só os concluintes. Não são utilizadas técnicas de mineração de dados como em Barbosa (2018), mas também é proposta uma ferramenta de simples utilização para visualização e análise, em que os dados da interação acadêmica com cada disciplina do curso podem também ser visualizados ao longo dos períodos letivos do curso, acrescentando-se a possibilidade de visualização por mais perspectivas como áreas de formação, fase de curso, $1^{a}$ curso da disciplina, matrículas fora da fase recomendada e matrículas antes da fase recomendada. Um importante diferencial é a possibilidade de visualização do percurso frequentemente realizado pelos alunos durante sua permanência no curso, permitindo verificar a evolução no currículo ao longo das fases letivas.

\section{Ambiente de Análise do Percurso Curricular}

A fim de compreender a análise do currículo sob a perspectiva da trajetória de aprendizagem, apresenta-se uma ferramenta que tem por finalidade identificar e visualizar a interação dos alunos com as disciplinas do currículo ao longo das fases do curso, analisando o percurso realizado sob diferentes perspectivas. A ferramenta é projetada como um instrumento de amparo aos gestores e docentes de uma Instituição de Ensino Superior - IES na avaliação e desenvolvimento dos currículos dos seus cursos. 
É preocupação deste empreendimento não provocar uma sobrecarga de trabalho aos docentes, problema destacado no trabalho de Leoniek (2018) ao identificar certa resistência por parte de professores e gestores em ter uma ferramenta a mais para gerir e alimentar com informações. Sendo assim, a inserção de dados via upload de arquivos csv é projetada e implementada sem a necessidade de inserção manual de cada informação, bem como uma interface de utilização que não exija conhecimentos técnicos mais específicos em tecnologias.

Para validação das funcionalidades implementadas no desenvolvimento deste ambiente de análise, procedeu-se à investigação dos percursos realizados por alunos de duas turmas do curso de Ciências da Computação da Universidade do Estado de Mato Grosso (UNEMAT).

\subsection{Base de Informações de Análise}

A coleta de dados necessários para as análises previstas é baseada nas informações fornecidas pelo sistema acadêmico vigente pela instituição Sistema Aberto de Gestão Unificada - SAGU, especificamente os históricos dos acadêmicos. Para identificar as informações acerca dos percursos curriculares, três entidades principais foram utilizadas, expostas na Figura 1.

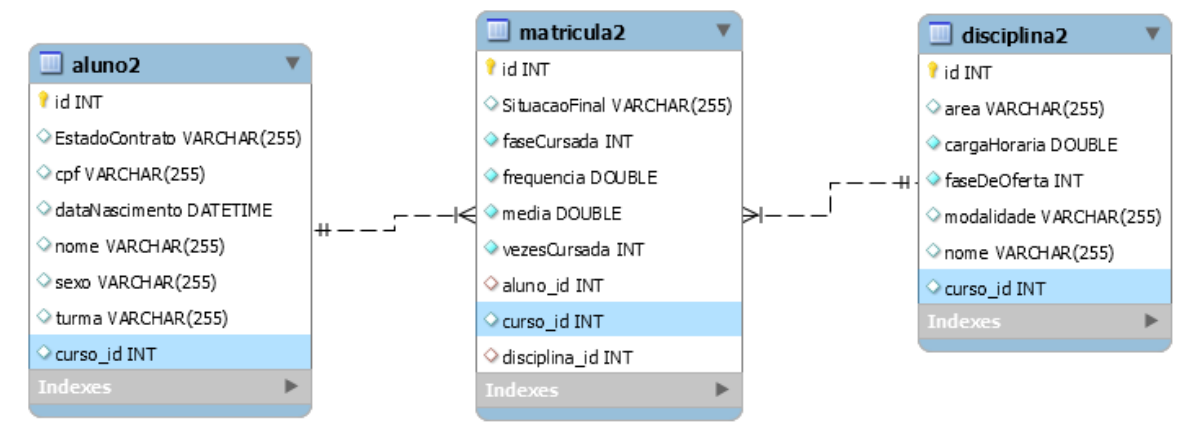

Figura 1. Diagrama Entidade Relacionamento

A matrícula é o vínculo que representa a interação entre o aluno e as disciplinas do currículo. Cada interação configura uma instância de matrícula, desta instância são coletados os resultados de frequência, média alcançada, fase na qual a disciplina está sendo cursada (baseada na data de ingresso do aluno, representado por sua turma) e quantas vezes cada disciplina está sendo cursada por um aluno. Há também mais duas entidades necessárias às funcionalidades do ambiente, o Curso ao qual cada aluno, matrícula e disciplina são vinculados e Usuário, que representa os usuários relacionados aos cursos.

Como pré-processamento dos dados fornecidos pelo sistema acadêmico, foi necessário somente a exclusão de informações dispensáveis, além da adaptação da disposição dos dados no arquivo de formato csv de forma computável. Apenas a situação final do aluno sofreu transformações, para representar estados de aprovação por média, aprovação por prova final, reprovação por média e reprovação por faltas. 


\subsection{Implementação e Funcionalidades}

A implementação inicial se concentrou na dinâmica de funcionamento do ambiente, norteada pela possibilidade de sua gestão e uso por docentes de diferentes áreas do conhecimento, não exigindo conhecimentos técnicos avançados. $\mathrm{O}$ acesso é baseado em cursos e em papéis. Assim, o acesso exige que seja realizado login e, após o acesso, o usuário só tem a visibilidade dos cursos aos quais está relacionado (Figura 2a). É possível estar relacionado com o curso como responsável ou como colaborador. $\mathrm{O}$ responsável é aquele que cria e insere informações sobre o curso, sendo possível adicionar colaboradores que poderão ter acesso às informações sem poder de edição. Para cadastrar um novo curso, não é necessária mediação com os mantenedores do ambiente, bastando apenas preparar corretamente o arquivo csv no modelo fornecido e realizar os uploads ao cadastrar o curso (Figura $2 b$ ).

(a)

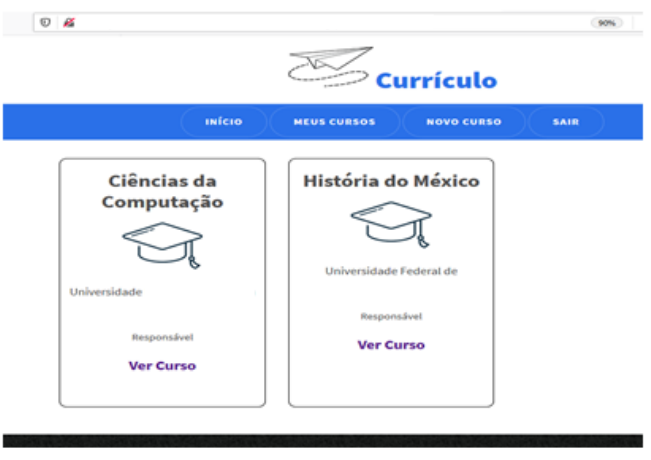

(b)

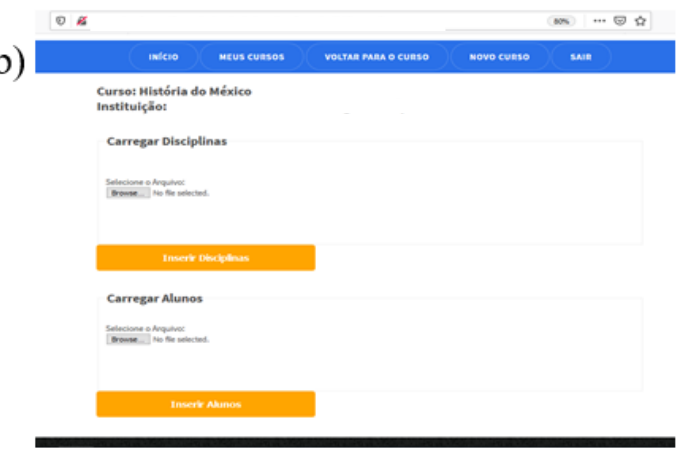

Figura 2. Interface Inicial e de Cadastro de Novo Curso

A possibilidade de compartilhar o acesso ao curso vislumbra uma característica colaborativa no ambiente, no qual os membros do Núcleo Docente Estruturante, Colegiado de Curso, ou mesmo todos os docentes do curso possam ter acesso e participar da avaliação e desenvolvimento do currículo.

Ao acessar o curso, informações básicas são exibidas já na tela inicial (Figura 3a), com o cômputo das seguintes informações: quantidade de alunos cadastrados, diplomados, evadidos e matriculados, quantidade de matrículas em disciplinas, quantidade de matrículas dentro da fase recomendada e fora desta fase, e quantidade de aprovações e reprovações obtidas no curso. Para visualizar os detalhamentos sobre as interações dos alunos com as disciplinas do currículo ao longo dos períodos letivos, são disponibilizados links para diferentes perspectivas de processamento das informações e visualização possíveis, sendo elas:

- Todas as Matrículas: detalha o total de ocorrências de matrículas por cada disciplina do currículo, e quais as quantidades realizadas na fase recomendada pelo currículo e fora desta fase.

- Detalhamento da disciplina: nesta exibição é possível clicar sobre qualquer disciplina e visualizar os detalhamentos de sua oferta, como exemplificado na Figura $3 b$.

- $1^{\circ}$ Matrícula: faz o mesmo do item anterior, porém considera somente a primeira matrícula do aluno na disciplina. 
- Reprovações todas matrículas: detalha a quantidade e percentual de reprovações ocorridas em cada disciplina, e a quantidade e percentual de reprovações quando ela é cursada na fase recomendada pelo currículo e fora da fase recomendada.

(a)

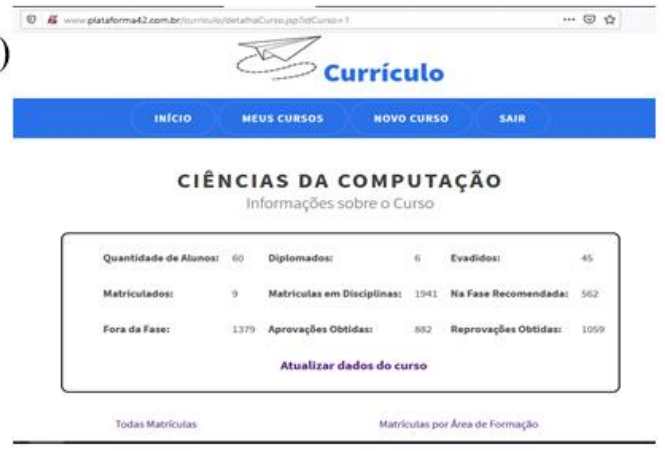

(b)

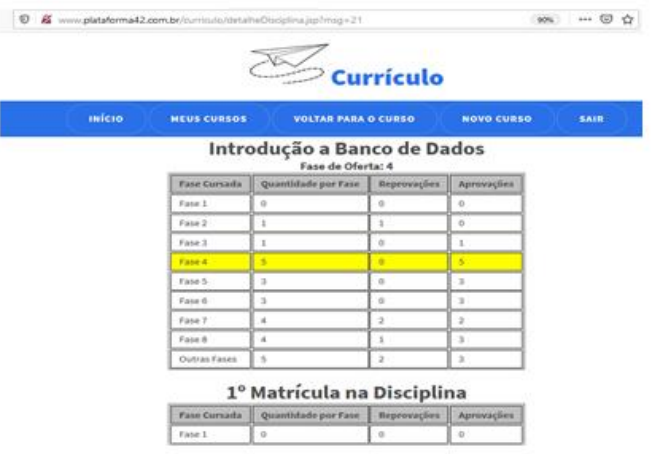

Figura 3. Informações do Curso e Detalhes da Disciplina

- Reprovações $1^{a}$ Matrícula: apresenta os mesmos detalhamentos sobre reprovações descritos anteriormente, porém computando somente quando a reprovação ocorre na primeira vez que o aluno cursa a disciplina.

- Matrículas por Área de Formação: agrupa as disciplinas nas áreas de formação previstas no currículo, e contabiliza o total de matrículas por área, matrículas na fase recomendada e fora da fase, $1^{\mathrm{a}}$ Matrícula, reprovações na fase e fora da fase recomendada, reprovações na $1^{\mathrm{a}}$ matrícula, matrículas realizadas em período anterior à fase recomendada e as reprovações e percentual quando a disciplina é cursada antes da fase recomendada.

- Trajetória Realizada: nesta perspectiva é construído, com base nas matrículas cadastradas, qual percurso curricular está sendo realizado pelos alunos de acordo com a quantidade de matrículas. Aqui é demonstrado quais disciplinas são as mais cursadas ao considerar a fase que o aluno está no curso, sua fase é determinada pela data do seu ingresso.

- Trajetória Realizada Reprovações: demonstra as ocorrências de menor desempenho quando a disciplina é cursada em uma determinada fase. Assim, para cada fase da trajetória dos alunos, são apresentadas as disciplinas nas quais mais surgem ocorrências de reprovações quando cursadas naquela fase.

- Trajetória Realizada Aprovações: assemelha-se ao tópico anterior, no entanto, identificando os melhores desempenhos, ou seja, as aprovações. São identificadas e exibidas as disciplinas nas quais mais aprovações são obtidas quando cursadas em uma determinada fase da trajetória dos alunos.

Reitera-se que todas as perspectivas são atualizadas dinamicamente quando novas matrículas são inseridas. Também são implementadas para serem adaptáveis para quaisquer formatos de cursos a serem cadastrados quanto às disciplinas, áreas de formação, quantidade de fases e disciplinas por fase. 
IX Congresso Brasileiro de Informática na Educação (CBIE 2020)

Anais do XXXI Simpósio Brasileiro de Informática na Educação (SBIE 2020)

\section{Análise do curso de Ciências da Computação}

Para validar as funcionalidades da ferramenta desenvolvida, tomou-se como objeto de análise um curso de Ciências da Computação, delimitando duas turmas, de ingresso em 2013/2 (40 alunos) e 2014/1(26 alunos), as quais foram acompanhadas até o semestre letivo de 2019/2. As informações necessárias foram retiradas do sistema acadêmico na forma de relatório, com o histórico de cada aluno gerado em formato csv.

Em um primeiro momento foi necessário compilar todos os históricos em um só arquivo utilizando somente os parâmetros necessários. Nesta etapa, foi identificado com estranheza casos de alunos em primeira fase cursando disciplinas muito avançadas no currículo, inclusive com pré-requisitos. Foi verificado que havia, nestas turmas, alunos que já faziam parte do curso há muitos semestres, e que reingressaram por um novo vestibular pois estavam em estado de jubilamento. Assim, foram retirados 6 alunos que se enquadravam nesta situação, pois a ferramenta não estava preparada para computar estados de "Aproveitamento de disciplina".

Após o tratamento inicial, foram carregados no ambiente os históricos de 60 alunos, os quais foram imediatamente processados, gerando informações compiladas dos dados carregados. As observações iniciais refletiram os graves problemas de evasão e retenção que afligem o curso. Mesmo decorridos 7 anos de ingresso destas turmas, apenas 6 alunos chegaram a diplomar-se, 9 ainda permanecem no curso e 45 evadiram.

A trajetória acadêmica dos alunos analisados gerou a interação de 1941 instâncias de matrículas em disciplinas do currículo, tendo como resultado 882 aprovações e 1059 reprovações. Ao considerar os períodos letivos, identificou-se uma grande discrepância entre as fases recomendadas pelo currículo e as fases em que os alunos realmente estão cursando as disciplinas, demonstrando 562 matrículas realizadas em disciplinas dentro da fase recomendada e 1379 fora da fase. Há diversos motivos que podem tangenciar a trajetória realizada pelos alunos. Neste sentido, a ferramenta oferece diferentes perspectivas de observação, que permitem uma melhor exploração do fenômeno observado.

Considera-se que a $1^{\mathrm{a}}$ matrícula na disciplina melhor representa o momento de escolha pelo aluno de qual disciplina cursar, já que após a primeira reprovação toda tentativa posterior de cumprir o crédito caracteriza uma matrícula fora da fase. Esta observação explicitou a existência de um gargalo na segunda fase do currículo, com forte impacto na trajetória dos alunos. Na perspectiva da ferramenta que exibe o total de matrículas fora da fase por disciplinas, as 5 disciplinas com o maior número de matrículas são desta fase (apenas Produção de texto e leitura fica de fora), porém, ao acessar a perspectiva de $1^{\mathrm{a}}$ matrícula, as mesmas disciplinas estão atrás das 30 disciplinas com maior quantidade de matrículas. Isso demonstra o custo ofertado por esta fase, pois a maioria das matrículas $(78,55 \%)$ são decorrentes de reprovações sucessivas.

O percurso gerado pela funcionalidade "Trajetória Realizada" demonstra uma importante característica sobre a execução e resultados do curso, e corrobora com o gargalo identificado anteriormente. É verificado que as disciplinas de Linguagens de Programação, Cálculo I, Geometria Analítica e Algoritmos II (todas recomendadas para a segunda fase) são disciplinas com maiores ocorrências em 4 fases do percurso 
(considerando a perspectiva de fases do aluno), e Introdução à Redes de Computadores é destaque em 3 fases do percurso. O percurso construído demonstra que a maioria dos alunos analisados levam até a $7^{\mathrm{a}}$ fase para cumprir todos os créditos da $2^{\mathrm{a}}$ fase. No seguimento do currículo, apenas Estágio I e Álgebra Linear demonstram um custo de avanço na trajetória do aluno, estando ambas como maioria de matriculados em duas fases.

Cabe ressaltar que não houve correlação em disciplinas sequenciais deste bloco de disciplinas. Algoritmos I, por exemplo, apresenta uma taxa de reprovação $(55,6 \%)$ inferior à sua disciplina sequencial, Algoritmo II (73,08\%). O inverso ocorre com Cálculo I com alta taxa de reprovações $(83.33 \%)$ contra uma menor taxa da subsequente Cálculo II (43,31\%).

O percurso frequentemente realizado demonstra uma dinâmica que impossibilita a conclusão do curso dentro do caso previsto, confirmado pelo fato de que os 6 únicos diplomados permaneceram de 9 a 13 semestres letivos no curso, para o qual é previsto 8 semestres em seu currículo.

Outra importante percepção proporcionada pela ferramenta trata-se da quantidade de disciplinas cursadas pelos alunos. $\mathrm{O}$ curso possui 52 disciplinas previstas no currículo, porém há 12 alunos que obtiveram de 60 até 93 instâncias de matrículas. Isso ocorre devido à permanência prolongada no curso e sucessivas reprovações. Ao observar os evadidos, verificou-se que 16 dos evadidos permaneceram com vínculo no curso até a $4^{\mathrm{a}}$ fase ( 2 anos no curso). Desse grupo 8 ainda permaneceram até a $8^{\mathrm{a}}$ fase cursando de 20 a 66 disciplinas antes de evadirem. Esta ocorrência traz uma importante reflexão sobre a evasão no curso: por esses resultados nota-se que ela não ocorre somente de maneira pontual na primeira fase em uma decisão imediata por parte do aluno. Evidenciou-se que $35.55 \%$ dos evadidos mantiveram 2 a 4 anos de vínculo com o curso, e talvez seriam passíveis de serem resgatados e mantidos no curso caso houvesse alguma intervenção no período adequado.

\section{Considerações Finais}

As funcionalidades planejadas e implementadas para a aplicação aqui apresentada, proporcionaram o processamento, compilação e exibição de informações sobre o curso, as quais não são adquiridas diretamente através do sistema acadêmico da instituição. Gerá-las manualmente, seria exaustivo e sujeito a muitos erros, talvez até impraticável, caso ampliada a dimensão da amostra. No entanto, há uma variedade de possibilidades a serem exploradas nos dados que a aplicação pode processar. $\mathrm{Na}$ validação com $\mathrm{o}$ curso de computação, por exemplo, identificou-se a necessidade de implementar funcionalidades para se obter a quantidade de matrículas por alunos evadidos em cada fase. Também se verificou a necessidade de considerar o aproveitamento de disciplinas. Sendo assim, espera-se que, com a utilização em diferentes cursos, surjam ricas colaborações e outros recortes que possam serem incluídos.

A análise do curso de Computação evidenciou uma trajetória de avanço sobre o currículo prejudicada por um conjunto de disciplinas específicas. Esta situação deve ser investigada com mais afinco pelos docentes do curso. Também se recomenda que haja continuidade na atualização e acompanhamento desses dados, de forma a planejar intervenções em tempo hábil, que possam evitar a evasão e sucessivas reprovações, uma 
vez que o longo vínculo mantido pelo aluno antes de evadir-se pode figurar uma oportunidade de tangenciar a trajetória deste aluno em uma direção positiva.

O planejamento do ambiente e a análise realizada do curso reforçou a compreensão de que abordar a trajetória de aprendizagem no desenvolvimento do currículo e manutenção do currículo é promissor, proporcionando que os docentes reflitam sobre o posicionamento e o ordenamento de cada componente curricular dentro de uma trajetória, que mesmo podendo seguir diferentes caminhos possíveis, direcionem os acadêmicos aos objetivos educacionais do currículo.

\section{Referências}

Anuradha, C. e Velmurugan, T. A data mining based survey on student performance evaluation system. 5th IEEE International Conference on Computational Intelligence and Computing Research, IEEE ICCIC 2014, (43-47). 2015.

Barbosa, A. et al. Using Learning Analytics and Visualization Techniques to Evaluate the Structure of Higher Education Curricula. Brazilian Symposium on Computers in Education (Simpósio Brasileiro de Informática na Educação - SBIE), [S.1.], p. 1297, ISSN 2316-6533. doi:http://dx.doi.org/10.5753. out 2017.

Canto Filho, A., Felipe Becker Nunes, R., \& Wagner, Manuel Zunguze, Kelly Hannel, Franco Simbine, R. M. e J. V. D. L. Trajetórias de Aprendizagem. In book: Trajetórias de Aprendizagem: teoria e prática, Edition: 1, Chapter: 1, Publisher: Amazon, Editors: José Valdeni de Lima, Manuel Constantino Zunguze, Kelly Hannel, Felipe Becker Nunes, pp.1-10. 2016.

Clements, Douglas \& Sarama, Julie. Learning trajectories: Foundations for effective, research-based education. Chapter Book. Learning over time : learning trajectories in mathematics education. Information Age Publishing, INC. Printed in the USA, 2014.

Confrey, Jere R. Seth Jones \& Garron Gianopulos. Challenges in Modeling and Measuring Learning Trajectories, Measurement: Interdisciplinary Research and Perspectives, 13:2, 100-105, DOI: 10.1080/15366367.2015.1055131. 2015.

Hall, Catherine E.A.Toward a model of curriculum analysis and evaluation - Beka: A case study from Australia, Nurse Education Today. Volume 34, Issue 3, Pages 343348, ISSN 0260-6917, https://doi.org/10.1016/j.nedt.2013.04.007. 2014.

Leoniek Wijngaards-de Meij \& Sigrid Merx. Improving curriculum alignment and achieving learning goals by making the curriculum visible, International Journal for Academic Development, 23:3, 219-231, 2018.

Lima, L. F. F. P., Silva, U. L. A. S, Silva, D. R. D. Análise de Dados de Percursos Curriculares dos Alunos de Ciência da Computação da Universidade Federal da Paraíba. RENOTE - Revista Novas Tecnologias na Educação. V. 17 N N $^{\circ}$, ISSN 1679-1916. https://doi.org/10.22456/1679-1916.99467. Dezembro, 2019.

Özüdoğru, F. Analysis of curriculum evaluation studies conducted in foreign language education: 2005-2016. Journal of Language and Linguistic Studies.14,113-134. 2019.

Waszak, J. G. N., Santos, S. V. Ambientalização Curricular no curso de Licenciatura em Ciências da Natureza: Análise à luz do indicador de Flexibilidade e Permeabilidade. revista portuguesa de pedagogia. 52-2, 69-87. 2018. 